\title{
Enhancing Mathematical Language through Oral Questioning in Primary Schools
}

\author{
Muhammad Sofwan Mahmud \\ Universiti Kebangsaan Malaysia, Malaysia \\ Universiti Putra Malaysia, Malaysia \\ https://orcid.org/0000-0002-0504-4622
}

\author{
Aida Suraya Md. Yunus, Ahmad Fauzi Mohd Ayub and Tajularipin Sulaiman \\ Universiti Putra Malaysia, Malaysia \\ https://orcid.org/0000-0002-8742-4855 \\ https://orcid.org/0000-0002-4313-2922 \\ https://orcid.org/0000-0002-4664-2637
}

\begin{abstract}
Fluency in mathematical language is essential in helping students to master mathematics content. This qualitative case study was conducted to describe how mathematics teachers apply mathematical language to students in the oral questioning process. Data were collected through observations, interviews, and field notes. Six mathematics teachers from six different primary schools were selected as participants of the study using a purposive sampling method. The data were then analyzed using a constant comparative method to identify the patterns and themes that emerged from the data obtained. The study found that students were questioned by emphasizing the correct pronunciation and were asked mathematical terms and keywords to improve their mathematical language ability through oral questions. To enhance mathematical language, the teacher also restated terms in the teachers' own words, asking using verbal-cloze questions, asking questions about mathematical terms repeatedly and using seeking-clarification questions. Thus, the use of various approaches in oral questioning had helped students to improve their fluency of mathematical language and enabled them to understand mathematical concepts better. Therefore, teachers need to understand the role played by oral questioning in the teaching of mathematical language to students.
\end{abstract}

Keywords: mathematical language; oral questioning; teaching mathematics 


\section{Introduction}

Effective use of oral questioning in the mathematics teaching process can develop students' mathematical thinking and help students develop a better understanding of the topics being studied (Desli \& Galanopoulou, 2017; Shahrill \& Clarke, 2014). Mahmud et al. (2020a) stated that one of the crucial functions of oral questioning is to help improve students' thinking towards understanding mathematical problems and finding solutions. Mathematical learning objectives will become more challenging to achieve if students have poor fluency and proficiency in mathematical language (Zhang \& Lin, 2015). Good mathematical language fluency can help strengthen students' mathematical senses to make connections with various mathematical concepts (Mohamad et al., 2009). Mohamad et al. (2009) further stated that the use of correct language facilitates students to communicate with mathematics and correct their misunderstanding of mathematical terms used in the classroom. Communication is part of the process of learning mathematics, and effective communication will create meaningful understanding in subjects taught to students.

Using the correct mathematical language is one of the essential skills in the process of teaching and learning mathematics, in addition to many other skills such as procedural skills and problem-solving skills (Ministry of Education Malaysia, 2014). It is also an essential element in the aspect of classroom communication in effective mathematics teaching. Effective communication in mathematics refers to the ability to convey information, and to understand and apply mathematical notations and language correctly (Idris, 2005). Students need to use the correct language and mathematical symbols to ensure that mathematical ideas can be correctly interpreted (Ahmad et al., 2006). Also, mastering the language of mathematics can help learners to understand mathematical concepts more efficiently and help students solve various mathematical problems at a higher level (Riccomini et al., 2015). Thus, understanding and mastering mathematical terms and languages can help students shape their mathematical senses and logic (Ryve et al., 2013).

Improving mathematical language skills is an essential aspect of teaching mathematics, especially at the primary school level. This process is a continuous process throughout one's education (Mahmud et al., 2020a). Thus, mastering mathematical language enhances students' ability to use mathematical vocabulary correctly and helps students to communicate mathematically in developing their overall mathematical skills (Morin \& Franks, 2009). Providing strong mathematical language support can enhance students' skills in solving various mathematical problems as well as in developing students' ability to clarify their ideas in mathematics language. Riccomini et al. (2015) explained that there are three primary purposes for emphasizing the language of mathematics. First is to help the understanding and memorization of the meaning of a mathematical word in the long-term memory. The second is to help students become fluent and retain the meaning of the word over time. The third is to assist students in using the mathematical language efficiently and accurately to clarify, thus allowing the formation of the concepts and mathematical relationships. 
There are many ways that teachers can use to implement the language of mathematics, such as repeating the mathematical terms frequently during the duration of learning (Morin \& Franks, 2009). They further explained that this would indirectly help build sharper memory of the term introduced and allow the student to pronounce correctly each word introduced. However, the best application of mathematical language should be combined with visual stimulation for a better understanding of the meaning or terms of mathematics introduced (Kanapathy, 2016). Lasiun (2016) explained that the application of mathematical concepts supported by visual stimuli could help students improve their mental reflection skills on a mathematical topic.

There is also a traditional way used by the teacher, which directly provides information to students on the term or mathematical language emphasized. However, this is found to be more teacher-centered and lack the active involvement of students in the learning process. Hence, among the approaches that teachers can use are through oral questioning strategies (McAninch, 2015). Through oral questioning, students will be more stimulated to actively think and to provide more information regarding the topics being discussed (Mahmud, 2019). Hence, the teaching of the mathematical language will be more active and help students' thinking to better understanding. Critical thinking is one of the factors that need to be considered to improve teaching performance of teachers (Sulaiman et al., 2017). Also, Riccomini et al. (2015) suggested some specific techniques to help students increase the vocabulary of mathematics, i.e. (a) explicit vocabulary instruction, (b) mnemonic strategies, (c) fluency building through multiple exposures, (d) games-like activities, and (e) technology applications. Besides, Marzano (2005) also proposed six important ways of incorporating mathematical language into teaching, as shown in Figure 1:

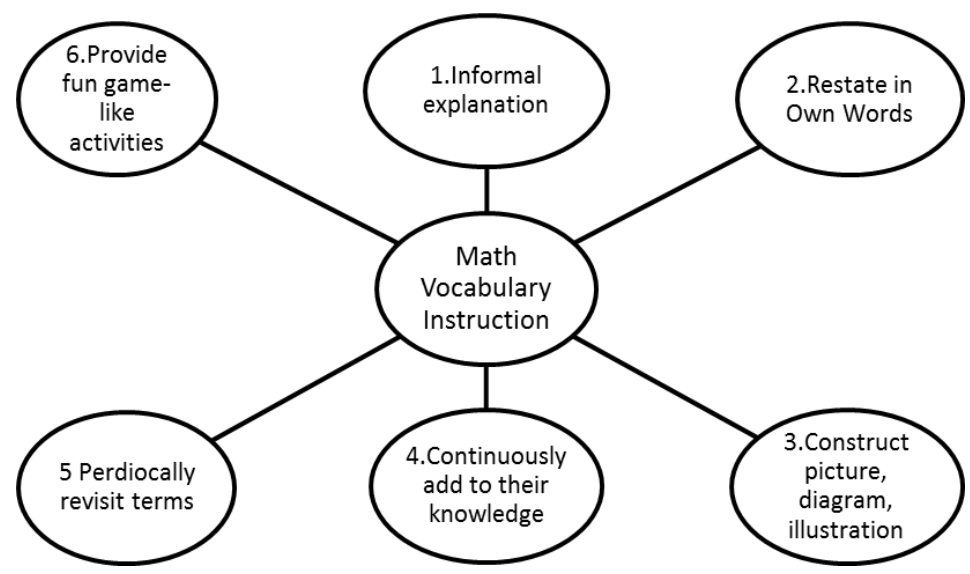

Figure 1: Concept map based on six recommendations by Marzano (2004) for effective vocabulary instruction

However, students' poor understanding of mathematical language may make it difficult for students to understand the mathematical concepts they have learned and to discourage them from solving various mathematical problems (Purpura \& Reid, 2016). Students cannot understand the different terms and symbols that are important in mathematical sentences. This may indirectly undermine students' confidence to learn mathematics to the extent that it can cause 
mathematic anxiety (Morin \& Franks, 2009). Also, there have been studies mentioning that students' weaknesses in understanding mathematical language well may lead to mathematical phobias (Okafor \& Anaduaka, 2013). Students need to understand the language of mathematics to assist the students' mathematical learning process better. Further research is needed on how the oral questioning process implemented in mathematics teaching can help students improve their mastery of the language of mathematics. This is because oral questioning is widely used in the teaching of mathematics (Mahmud, 2020).

Little is known about the language of mathematics and how it is applied through the oral questioning process. According to a study by Mohamad et al. (2009), teachers still do not understand the importance of emphasizing mathematical language to students, and mathematical language is seen as less important than the mastery of mathematical concepts and skills. A previous study by Mahmud et al. (2020b) on oral questioning also found that teachers were less concerned with the application of mathematical language as compared to the cognitive aspects. Hence, this study was conducted to describe how oral questioning in the mathematics teaching process was used as a means to enhance students' mathematical language. This general question entails two findings, (1) the oral questioning in the mathematics teaching process and (2) how it enhances students" mathematical language.

\section{Methodology}

This study was a qualitative study. The case study method was chosen to help the researcher gain an in-depth understanding of enhancing mathematical language in the process of oral questioning in mathematics teaching in primary schools. The study involved six participants from six different schools in a district that were selected using a purposive sampling technique. Multiple sources of data were collected, including two interviews (Appendix 1) (i.e., initial interview and stimulated-recall interview) for each teacher, nonparticipant observation, and field notes by the researcher for each interview and observation. The researcher developed instruments for observation and initial interviews while instrument for stimulated-recall interviews was adapted from McAninch's (2015) study. This study used semi-structured face-to-face interviews (Creswell, 2014) as a guide to the researcher to ensure that the interview process aligns with the objectives and research questions.

The interview questions developed by the researcher are based on the theoretical framework and literature available in the previous study will ensure that the researcher did not miss every critical point that was the focus of the research. All the instruments used in this study were reviewed and validated by six experts in the field of mathematics education. The use of various data collection techniques allows the researchers to triangulate the data at the analysis level while also confirming the results obtained (Creswell, 2013). In this study, the analysis was conducted using the continuous comparative method where data from the verbatim interviews were compared between each study participant and analyzed using Atlas.ti 8 software through open coding, axial coding and selective coding for themes and subthemes (Kolb, 2012). Miller et al. (2012) 
stated that the validity and reliability of a study refer to the extent to which the study's findings can accurately and consistently represent the phenomenon studied. Therefore, the researcher had used several methods to enhance the validity and reliability of the study using the triangulation method, member checking and peer review.

\section{Findings}

The ages of the research participants ranged from 27 to 50 years old (Table 1). Teacher Ana, Teacher Nadia and Teacher Ada were in their twenties, and all of them have less than four years of teaching experience. On the other hand, Teacher Raha, Teacher Azah and Teacher Roza were more than 40 years of age and had more than 20 years of teaching experience. All the participants obtained undergraduate degrees in Mathematics Education. Hence, the participants were considered to have the credibility, knowledge and skills to teach mathematics.

Table 1: Educational Background and Teaching Experience of the Participants

\begin{tabular}{|l|c|c|c|c|c|c|}
\hline & Ana & Nadia & Ada & Raha & Azah & Roza \\
\hline Age & 28 & 27 & 28 & 46 & 50 & 44 \\
\hline Mathematics Teaching Experience & 4 & 3 & 4 & 20 & 23 & 23 \\
\hline Academic Qualification & \multicolumn{6}{|l|}{ achelor's Degree in Mathematics with Education } \\
\hline
\end{tabular}

Based on the findings, it is found that there are various strategies used by teachers in the oral questioning process to apply mathematical language to students. Excerpts from the teacher's observations as well as excerpts from the interviews conducted support each of the explanations discussed in the findings. Examples of labels for observations are [Azah, P3/12452-12723] where 'Azah' (participant's name), 'P3' (third observation for Teacher Azah) and '12452-12723' (sentence numbering in the observation document analyzed). For interview transcripts, the researcher used the label 'SRI' or ' $\mathrm{II}$ ' where 'SRI' refers to the stimulated-recall interview while 'II' refers to the initial interview. For example, the label [Roza, SRI3/4751-5047] refers to 'Roza' (participant's name), 'SRI3' (third stimulated-recall interview), and '4751-5047' refers to the sentence numbering in the interview transcript document. Besides, for the data involving field notes, the researcher labelled it as 'NL' such as [Ada, NL/17082018] where 'Ada' refers to the participant, NL (field note) and '17082018' refer to the date that the field note was taken, which was August 17, 2018.

\section{Applying mathematical language in the process of oral questioning conducted in the process of teaching mathematics}

a) Asking students to pronounce the information in the question correctly The study found that teachers emphasized the ability to pronounce words, mathematical phrases as well as giving information contained in the question given. This was strongly emphasized by Teacher Roza based on the excerpt of the follow-up interview conducted with her in which she explained that "... students must know to mention if they have units, decimal points, correct numbers, what operations, how to write symbols." [Roza, SRI3/4538-4671]. Teacher Azah also expressed the same opinion that students need to emphasize the correct pronunciation. Teacher Azah said, "this is a way for us to introduce 
students to the aspects of mathematics language and important words that students need to understand in learning mathematics" [Azah, SRI1/2117-2991]. Besides, Teacher Azah also stated that it is important to emphasize the pronunciation as highlighted in her explanation as follows:

"For example, when it comes to decimals, it is important to read and pronounce the decimal numbers correctly. For weak students, it is usually when we tell them to read; they will read like fourteen-point twenty (14.20). It was supposed to be fourteen point two zero, so the student mispronounced it. So we want to correct how to read decimal numbers and indirectly help students to remember the concept of decimal numbers" [Azah, SRI 2/12496-13084].

Based on these explanations, the study found that teachers have the opportunity to correct students' mistakes and weaknesses by correcting the pronunciation of the student and teacher can also be joining the students in recalling the lessons learned to help students solve math problems better.

b) Ask students about mathematical terms and keywords

Also, participants asked questions on mathematical terms, phrases and keywords to help students understand the requirements to answer questions found in a text [Ana, NL/ 09082018]. In this context, questions relating to terms, phrases and keywords were introduced and emphasized to students as factual or descriptive information as well as reinforcing mathematical vocabulary. This can be seen based on the verbatim example of a teacher's teaching, as shown below:

Teacher: Okay. What is the name of this fraction? A whole number meets a proper fraction, what does it mean? What kind of fraction is that? It is a mixed fraction. Please remember.

[Ana, P1/10745-10844]

Teacher: Who knows what volume is? What do we mean by volume?

[Nadia, P3/300-396]

Based on the verbatim transcription of the lesson, Teacher Ana asked the students questions about the term fraction. Similarly, Teacher Nadia had also emphasized on the term by asking about volume [Nadia, NL/25092018]. These questions are examples of conceptual terms that teachers often refer to in their teaching. Questions related to the term are commonly repeated by teachers to help students understand and then form a coherent mental framework based on their understanding. The participants also explained that the terms related to the mathematical concepts being discussed were the fundamental concepts that students had to understand before proceeding to the next concept. Teacher Ada told this during the stimulated recall interview on the teaching that she had conducted earlier on:

Teacher Yes, the purpose of the question is to give students an understanding of the mathematical terms and what the 'perimeter' really means before continuing to teach. 
Researcher Oh, okay. So in Year 4, the student did not know what the perimeter meant?

Teacher They may know but a year has passed, and perhaps most of them have forgotten the mathematical concepts they have learned. So teachers need to stimulate their thinking to help them recall essential terms in math.

[Ada, SRI 1/10419-10532]

c) Restate in own words

It was also noticed that some teachers restated mathematical phrases in their own words. They used some other words/terms for the mathematical terms that they are teaching. For example, in Teacher Azah's teaching, the word 'mole' replaced phrases such as 'decimal point' and the phrase 'moving decimal point' was replaced with the word 'worm' [Azah, NL / 16102018]. Teacher Ana used the word 'a yo-yo' to replace the phrase unknown number and the multiple ten phrases with the words 'special number' [Ana, NL / 09082018].

Teacher Azah expressed her view that using her own words to explain the mathematical concepts could help students to understand them more effectively while assisting the students in remembering the terms more easily:

"... The words I use or rephrase in my own words are meant to make it easier for students to understand and remember. Because it's a bit difficult for them to remember using the term moving the decimal point."

[Azah, SRI 1/1190-1768]

d) Asking students using verbal-cloze questions

Based on the observation and verbatim analysis of the teaching, there were also questions based on terms and keywords that teachers asked students in the form of 'verbal cloze' which is a 'fill in the blank' question. The question is a shortform question that allows students to fill in the blank orally to complete the sentence. Emphasis on the correct vocabulary of mathematics is vital to help students better understand the content of learning.

Teacher: A typical square has...?

Student: $\quad$ Same long side

[Ada, P1/5427-5493]

Teacher No...7 means seven-point....?

Student Zero

[Ana, P1/13269-13333]

The verbatim excerpts from the lesson above are examples of 'fill in the blank' questions posed by Teacher Ada and Teacher Ana in their teaching sessions. In the example given by Teacher Ada, the students emphasized on the concept of 'same long side' for a square. Verbal-cloze questions also serve as a reflection for students to provide the teacher's desired answer [Ana, NL / 09082018]. This is evident when Teacher Ana also used the 'fill in the blank' question to explain the decimal using the keyword 'zero'. 
e) Ask questions repeatedly

The study also showed that teachers often emphasized mathematical language by repeating terms, phrases or concepts through oral questions. In this context, teachers often ask questions about new facts or words introduced in mathematics teaching. The following excerpt shows examples of how teachers repeat questions to emphasize words in their application of mathematical language:

$\begin{array}{ll}\text { Teacher } & \text { What is the name of this line? (Teacher shows students } \\ & \text { the parallel lines drawn on the whiteboard) } \\ \text { Student } & \text { Parallel lines. (students answered as a group) } \\ \text { Teacher } & \text { Okay again. What's the name of this line? } \\ \text { Student } & \text { It is a parallel line } \\ \text { Teacher } & \text { Okay, Adib. What is the name of this line? (The teacher } \\ & \text { directs a student to answer the question) } \\ \text { Student } & \text { Parallel line. } \\ \text { Teacher } & \text { Okay. Good. }\end{array}$

[Nadia, P2/4718-4790]

Based on the above excerpt, the questions were asked repeatedly to ensure that students fully understand the new word that was introduced by the teacher and was supported by diagrams to help students' understanding. This was stated by Teacher Nadia, "so that students can really remember the words or concepts that are explained to them and they will also understand better when teachers use diagrams as visual support" [Nadia, SRI2 / 3746-4118].

Besides, questions such as these are often asked in the form of oral quizzes to increase students' interest and participation. Questions such as mathematics formulas and basic facts are frequently asked by teachers to ensure students are familiar with the words and to facilitate students to solve a variety of mathematical problems.

Teacher Well. I will ask questions. Who can answer, please raise your hand? Okay. Please name the fraction I will

Student Proper Fraction

Teacher Good. $\frac{8}{3}$ ?

Student Improper fraction

Teacher Good ... $2 \frac{4}{9}$ ?

Student Mixed fraction

Teacher Okay. Good.

Based on the above excerpt, teachers give quizzes to help students remember important mathematical terms related to these types of fractions. Teacher Ana explained, "teachers need to ask students regularly and frequently so that they can remember the math terms. Thus, they will be familiar with the words in the exams." [Ana, SRI1 / 3617-3718]. 
f) Using seeking-clarification questions

In helping students improve their fluency in mathematical language, the participants had also frequently asked questions to help clarify student thinking and explore the origins of students' thinking, mathematical concepts and the content of the lessons being taught. In this way, students will try to explain their answers to teachers using the correct mathematical language. Here is an example of how teachers use questions to ask for clarification in mathematics teaching:

Student 15 meters.

Teacher How do you get 15 meters? Please explain.

Student 1.5 meter multiply by 10, so we get 15 meters.

Teacher Okay good. The answer is 15 meters.

[Roza, P2/3049-3422]

Teacher So, how we can find length $M R, R S, S N$ ?

Student We have to divide by 3.

Teacher Okay. Please explain?

Student Because we have three equal parts.

[Nadia, P1/9672-9831]

Based on the examples of the quotations in the verbatim transcriptions of Teacher Roza and Teacher Nadia's teaching, the researcher found that teachers used questions to ask for clarification, by asking students to explain how they got the answer and to encourage students to provide a sound mathematical explanation. Teacher Roza said that by asking students to explain their answers, students would try to use mathematical language to explain their answer to teachers.

"This is a time when students can try to speak and practice the mathematical language. So, when they get used to it, they will be more fluent in using the mathematical language." [Roza, SRI3/1166-1400]

Also, questions asking for clarification can play a role in helping teachers gain information and understand the extent to which students are developing and understanding the content of the lessons discussed [Azah.NL/18102018]. The information is used by teachers as assessment information to make decisions about the teaching process, as explained by Teacher Azah, "... so we can assess the students' knowledge, and from there, we can make the decision to continue or to repeat." [Azah, SRI 1/2570-2953].

\section{Discussion}

The findings showed that there were a variety of approaches used by a mathematics teacher to encourage fluency of mathematical language to students through oral questioning. As discussed earlier, oral questioning plays a significant role in helping students to improve their skills and understanding of mathematics learning (Mahmud et al., 2019; Wong, 2015). Thus, it is not surprising that oral questions are also used by teachers in improving students' mathematical language skills. The findings showed that teachers asked students to extract information contained in the text of the question by emphasizing on the correct pronunciation of the mathematical terms and vocabulary. The ability 
to correctly pronounce the terms and vocabulary in mathematics is one of the essential things to be acquired before students are provided with the explanation on the meaning of the words. This helps students to understand the mathematical concepts they have learned. For example, teachers asked students on how to state decimal numbers correctly. There may be students who state decimal number '2.56' (two-point five-six) as 'two-point fifty-six'. This allows teachers to correct the mistakes of the students and at the same time, the teacher can also help students to recall previous lessons. This indirectly fulfills one of the learning standards that teachers need to meet during the mathematics teaching process, which is the ability to pronounce the correct math phrase (Ministry of Education Malaysia, 2014).

Teachers were also asking keyword-related questions specifically in text-related questions in teaching mathematical language to students. This is in line with a study by McAninch (2015) that found that teachers also used questions related to mathematical terms and keywords as one of the ways to apply mathematical language to students. The emphasis on keywords in mathematical problem solving is one of the essential criteria in the language of mathematics that helps students understand the needs of a given mathematical problem in solving a problem. A good understanding of mathematical keywords can have a significant impact on the development of students' mathematical language skills as well as the development of mathematical comprehension itself (Mohamad et al., 2009). Vocabulary for keywords such as 'amount', 'balance', 'difference', 'more than' and 'less than' will help students better understand mathematical problems. Thus, continually asking students about the keywords and terms used in a mathematical question can provide students with guidance in solving the mathematics questions and at the same time, improve students' understanding and skills in mathematics. This is supported by Riccomini et al. (2015) who stated that the ability to effectively communicate (expressively and receptively) through the language of mathematics requires mathematical understanding; a robust vocabulary knowledge base; flexibility; fluency and proficiency with numbers, symbols, words, and diagrams; and comprehension skills.

However, students' difficulty in understanding mathematical language can have a significant impact on mastery of mathematical concepts encountered by students (Mohamad et al., 2009). This is because the findings of this research showed that there are teachers who restated terms in their own words in mathematics teaching. Marzano (2004) also stated that restating in own words can help in students understanding of vocabulary. For example, Teacher Azah used the word 'mole' for 'decimal point' and the word 'moving decimal point' was replaced with the word 'worm'. Besides, replacing mathematical terms with other words is also seen as a form of communication support in the mathematics teaching process (Riccomini et al., 2015).

However, the researcher thinks that, in helping students to develop fluency in mathematical language, teachers should use standard mathematical language or mathematical terms in a more dynamic, flexible and creative way so as not to confuse students understanding. In this case, teachers need to be wise in 
selecting techniques that are appropriate to the students' ability to apply standard mathematical language to students so that students' relational understanding can be better stimulated. Ahmad et al. (2006) explained that confusion about mathematical terms is a problem that students face, and this makes it difficult for students to understand and use mathematical terms. This is because mathematics term is the standard term used in any mathematics curriculum. This should be taken seriously because in global mathematical assessments such as TIMSS and PISA, standard language and mathematical terms are used. This may create difficulty for students in understanding the terms used.

Teachers also used verbal cloze questions as a hint if students cannot express using the correct vocabulary. This is a short-form question in the middle of a sentence to allow students to fill in the blank orally to complete the sentence. This is in line with the oral questioning framework introduced in Chin's (2007) study in which teachers reflect on oral questions posed to encourage students' response. Thus, by trying to guess the words through the teacher-provided reflections, they can train students to try to recall the math term that they had previously learned. Therefore, it can prepare students to strengthen their proficiency and ability in the language of mathematics.

Studies have also found that teachers frequently ask questions to improve students' memory and understanding of math terms. Joseph et al. (2012) emphasized that by regularly stimulating students to repeat new words, students can enhance their fluency in mathematical language. This will allow students to be more prepared for the essential things to be tackled in solving various math problems, as well as instilling their confidence, as they are already familiar with the mathematical terms that are regularly repeated to them (Mahmud et al., 2020b). However, repetition should also be supported by visual stimuli, such as using diagrams or various concrete materials to help students create a clearer picture of the mathematical terms being emphasized. It indirectly strengthens students' visualization skills in solving mathematical problems where visualization skills are the cognitive or mental processes of an individual that connects internal constructs with things that are happening in their environment. Applying visualization skills can help students understand mathematical concepts and help students solve various mathematics problems (Tambychik \& Meerah, 2010).

The study also found that teachers also asked questions that require students to clarify their answers. The asking questions approach requires the teacher to ask the student to explain further the answer given to the teacher. This finding is in line with the results of McAninch (2015) and Paul and Elder (2007) who had found similar findings. In this context, the teacher asks the students to think again and justify the answer. This indirectly provides the opportunity for students to practice the use of mathematical language by trying to explain the answer given. Thus, when students can inform teachers in the correct language of mathematics, it will help them to understand the mathematics questions or problems better and to plan for the solutions. Not only that, by asking questions 
to ask for clarification from students, it also promotes high-level thinking and communicative competencies such as clarification, submission and justification, as well as a need for students to participate in meaningful and genuine conversation and teaching exchanges between students and teachers (Gaspard, 2013; Kaya et al., 2014; Shahrill \& Clarke, 2014). It is also an application of mathematical language elements in which students' communication skills in mathematics can be improved.

Thus, teachers can develop students' mathematical language through the implementation of oral questioning in mathematics teaching in many ways. Students need to be exposed to a better understanding of mathematical language in order to ensure a better understanding of mathematical concepts. Failing to apply mathematical language skills will make it difficult for students to solve more complex mathematical problems and impede their ability to think at a higher level. The traditional method of providing students with a direct explanation of the standard mathematical language does not encourage students to think and even lessens interaction between teachers and students. The use of oral questioning to improve students ' mathematical language is, therefore seen as a more meaningful approach as it works more effectively to encourage students to think and increase student's involvement in the mathematics teaching process.

\section{Conclusion}

It is found that oral questioning plays a significant role in helping students develop their comprehension of mathematical terms, based on the discussions that have been made. This study highlighted the various approaches used by mathematics teachers in primary schools to help students improve their mathematical language skills through oral questioning. It also provided an overview of the impact of mathematical language mastery on students to ensure that students can better understand mathematical concepts. This indirectly provides a new perspective about the role that oral questioning plays in mathematics teaching. Thus, oral questioning is not only used to enhance students' thinking but also plays a significant role as an effective means of helping students improve their mastery of mathematical language. This study also seeks to expand the literature of the research by providing a deeper understanding of how teachers in mathematics can develop the language skills and mastery of mathematics for students. This is important because oral questioning takes up most of the mathematical teaching processes that have been implemented (Wilen, 1991). Rich development and understanding of mathematical language are essential for students to actively engage with the planned teaching activities and help them develop meaning about mathematics. Teachers should always use oral questioning to provide students with the best possible support for their understanding of mathematical language, rather than simply providing them with direct explanations during the teaching and learning activities. Consequently, the researcher proposes further studies to be conducted on how oral questioning process can be successfully implemented in improving students' mathematical language skills. 


\section{References}

Ahmad, S., Zawawi, T., \& Omar, A. (2006). Isu-isu dalam pendidikan matematik [Issues in mathematics education]. Utusan Publications.

Chin, C. (2007). Teacher questioning in science classrooms: Approaches that stimulate productive thinking. Journal of Research in Science Teaching, 44(6), 815-843.

Creswell, J. W. (2013). Research Design: Qualitative, Quantitative, and Mixed Methods Approaches. California: SAGE Publications, Incorporated.

Desli, D., \& Galanopoulou, E. (2017). Questioning in Primary School Mathematics: An Analysis of Questions Teachers Ask in Mathematics Lessons. 3rd International Symposium on New Issues on Teacher Education, 97.

Gaspard, C. (2013). Secondary Mathematics Student Teachers' Questions and Responses in Whole Class Discussion: Influences on Instructional Decisions (Doctoral thesis). University of California.

Idris, N. (2005). Pedagogi dalam pendidikan matematik [Pedagogy in mathematics education]. Utusan Publications.

Joseph, L., Eveleigh, E., Konrad, M., Neef, N., \& Volpe, R. (2012). Comparison of the Efficiency of Two Flashcard Drill Methods on Children's Reading Performance. Journal of Applied School Psychology, 28(4), 317-337.

Kanapathy, G. (2016). Kemahiran Visualisasi Dalam Mata Pelajaran Matematik Dalam Kalangan Murid Tahun 5 Di Sebuah SJKT Daerah Kuala Muda Yan, Kedah [Visualization Skills in Mathematics Subjects Among Year 5 Students at a Kuala Muda Yan District SJKT, Kedah]. International Seminar on Generating Knowledge Through Research, UUM-UMSIDA, 1(October), 909-916. https://doi.org/http://dx.doi.org/10.21070/picecrs.v1i1.629

Kaya, S., Kablan, Z., \& Rice, D. (2014). Examining question type and the timing of IRE pattern in elementary science classrooms. International Journal of Human Sciences, 11(1), 621-640. https:// doi.org/10.14687/ijhs.v11i1.2730

Kolb, S. M. (2012). Grounded Theory and the Constant Comparative Method: Valid Research Strategies for Educators. Journal of Emerging Trends in Educational Research and Policy Studies, 3(1), 83-86.

Lasiun, M. (2016). Keberkesanan Kaedah Visualisasi: Meningkatkan Keupayaan Menyelesaikan Masalah Matematik Berayat [The Effectiveness of Visualization Methods: Improving the Ability to Solve Lifetime Mathematical Problems]. International Seminar on Generating Knowledge Through Research, UUM-UMSIDA, 1(1), 687-698. https:// doi.org/10.21070/ picecrs.v1i1.542

Mahmud, M. S. (2019). The Role of Wait Time in the Process of Oral Questioning in the Teaching and Learning Process of Mathematics. International Journal of Advanced Science and Technology, 28(16), 691-697.

Mahmud, M. S. (2020). Level of Oral Questions Used by New and Experience Teachers in Mathematics Teaching in Primary Schools. International Journal of Psychosocial Rehabilitation, 24(8), 3533-3541.

Mahmud, M. S., Yunus, A. S. M., Ayub, A. F. M., \& Sulaiman, T. (2020a). The use of oral questioning in inculcating values in mathematics for primary school students. Universal Journal of Educational Research, 8(3), 1-8. https://doi.org/10.13189/ujer.2020.081601

Mahmud, M. S., Yunus, A. S. M., Ayub, A. F. M., \& Sulaiman, T. (2020b). Types of Oral Questions Used by Teachers in Mathematical Problem Solving Teaching in Primary School Mathematics Teaching. International Journal of Psychosocial Rehabilitation, 24(06), 2278-2292.

Marzano, R. J. (2004). Building background knowledge for academic achievement. Alexandria: Association for Supervision and Curriculum Development. 
McAninch, M. J. (2015). A Qualitative Study Of Secondary Mathematics Teachers ' Questioning, Responses, And Perceived Influences ( $\mathrm{PhD}$ thesis). University of Iowa.

Miller, T., Birch, M., Mauthner, M., \& Jessop, J. (2012). Ethics in qualitative research. Thousand Oaks, CA: SAGE Publications.

Ministry of Education. (2014). Dokumen Standard Kurikulum Dan Pentaksiran Matematik: Tahun Enam [Curriculum and Assessment Standard Document: Year Six]. Putrajaya: Ministry of Education Malaysia.

Mohamad, B., Esa, A., \& Warman, M. Y. A. H. J. H. S. (2009). Komunikasi Dalam Matematik Dalam Kalangan Kanak-Kanak [Mathematical Communication Within Children]. Persidangan Kebangsaan Pendidikan Sains Dan Teknologi 2009 [National Conference on Science and Technology Education 2009], 1-17.

Morin, J. E., \& Franks, D. J. (2009). Why Do Some Children Have Difficulty Learning Mathematics? Looking at Language for Answers. Preventing School Failure: Alternative Education for Children and Youth, 54(2), 111-118. https://doi.org/10.1080/10459880903217861

Okafor, C. F., \& Anaduaka, U. S. (2013). Nigerian School Children and Mathematics Phobia: How the Mathematics Teacher Can Help. American Journal of Educational Research, 1(7), 247-251. https://doi.org/10.12691/education-1-7-5

Paul, R., \& Elder, L. (2007). Critical Thinking: The Art of Socratic Questioning. Journal of Developmental Education, 31(1), 36-37. https://doi.org/10.1037/027900

Purpura, D. J., \& Reid, E. E. (2016). Mathematics and language: Individual and group differences in mathematical language skills in young children. Early Childhood Research Quarterly, 36, 259-268. https:// doi.org/10.1016/j.ecresq.2015.12.020

Riccomini, P. J., Smith, G. W., Hughes, E. M., \& Fries, K. M. (2015). The Language of Mathematics: The Importance of Teaching and Learning Mathematical Vocabulary. Reading and Writing Quarterly, 31(3), 235-252. https:// doi.org/10.1080/10573569.2015.1030995

Ryve, A., Nilsson, P., \& Pettersson, K. (2013). Analyzing effective communication in mathematics group work: The role of visual mediators and technical terms. Educational Studies in Mathematics, 82(3), 497-514. https://doi.org/10.1007/s10649-012-9442-6

Shahrill, M., \& Clarke, D. J. (2014). Brunei Teachers' Perspectives on Questioning: Investigating the Opportunities to "Talk" in Mathematics Lessons. International Education Studies, 7(7). https://doi.org/10.5539/ies.v7n7p1

Sulaiman, T., Kuppusamy, S. K., Ayub, A. F. M., \& Rahim, S. S. A. (2017). Relationship between Critical Thinking Disposition and Teaching Efficacy Among Special Education Integration Program Teachers in Malaysia. AIP Conference Proceedings 1795, 020025.

Tambychik, T., \& Meerah, T. S. M. (2010). Students' difficulties in mathematics problemsolving: What do they say? Procedia - Social and Behavioral Sciences, 8(5), 142-151. https:// doi.org/10.1016/j.sbspro.2010.12.020

Wilen, W. W. (1991). Questioning Skills For Teachers what Research Says to the Teacher. (3rd Edition). Washington: National Education Association.

Wong, K. Y. (2015). Use of Student Mathematics Questioning to Promote Active Learning and Metacognition. In S. J. Cho (Ed.), Selected Regular Lectures from the 12th International Congress on Mathematical Education (pp. 877-895). https://doi.org/10.1007/978-3-319-17187-6_49

Zhang, X., \& Lin, D. (2015). Pathways to arithmetic: The role of visual-spatial and language skills in written arithmetic, arithmetic word problems, and nonsymbolic arithmetic. Contemporary Educational Psychology, 41, 188-197. https://doi.org/10.1016/j.cedpsych.2015.01.005 


\section{Appendix 1}

\section{INTERVIEW QUESTIONS}

\section{Initial Interview: Background Information and Philosophy of Questioning}

I. Introduction

A. Explain why participant was selected

II. Focus the classroom

A. To obtain a general philosophy of their purpose(s) of questioning in III. Interview Questions

A. How long have you been teaching?

B. Tell me about the students you are currently teaching. questioning?

a. How does the culture of your classroom support quality C. How would you describe your teaching philosophy?

a. Is your classroom student-centered? What are the student and teacher roles in your mathematics classroom?

D. What do you know about teacher questioning as an instructional practice?

E. How would you describe your philosophy of questioning in the classroom?

F. Do you have any sort of classification of questions in your mind? Explain.

G. What are your criteria for judging whether or not your questioning is eliciting the desired outcomes?

H. Do you think about your questions or question asking anytime outside of class? When and in what ways?

I. How do you respond to student answers? What types of feedback do you give? How do students expand upon correct answers? How do students interact with one another and initiate questions?

classroom?

J. What experiences have influenced how you ask questions in the

(Questions were taken from McAninch, M. J. (2015). A Qualitative Study of Secondary Mathematics Teachers' Questioning, Responses, And Perceived Influences. University of Iowa.) 


\section{Stimulated-Recall Interview: Reflective Interview on Instructional Decision Making}

I. Introduction

A. Explain what an SR interview is

II. Focus

A. Question asking during the videotaped teaching episode

III. SR Rules

A. Can stop video at anytime

B. Distinguish between actual recall and new observations

IV. Orient

A. Participant gives brief description of purpose of teaching episode

B. SR addresses following issues:

1. Teacher's perspective on what happened in the episode

2. What teacher was trying to accomplish

3. What information were choices based on

V. Questions (asked each time tape is stopped)

A. Can you recall any of your thoughts when you asked that question?

B. Did anything that occurred in class influence your decision to ask that question? Explain.

C. What information did you base that decision on?

D. How did you decide which responses were appropriate?

E. Was there anything else you thought of doing at that point but decided against?

What influenced this decision?

F. Would you like to share anything else about this teaching episode?

VI. Thank participant again for their time and interest.

(Questions were taken from McAninch, M. J. (2015). A Qualitative Study of Secondary Mathematics Teachers' Questioning, Responses, And Perceived Influences. University of Iowa.) 